\title{
Democracia supranacional, cosmopolitismo e direitos humanos segundo Habermas e à luz de Kant
}

\author{
Supranational Democracy, \\ Cosmopolitanism and Human Rights \\ from Habermas and in the light of Kant
}

\author{
Francisco Jozivan Guedes de Lima \\ Universidade Federal do Piauí (UFPI) \\ Orcid 0000-0003-4483-8393 \\ jozivan2008guedes@gmail.com
}

Delamar José Volpato Dutra

Universidade Federal de Santa Catarina (UFSC)

Orcid 0000-0002-3738-7865

djvdutra@yahoo.com.br

Resumo: O artigo aborda a articulação habermasiana entre democracia supranacional e direitos humanos à luz do cosmopolitismo de Kant. Para Habermas, Kant foi emblemático na proposta de um direito cosmopolita, todavia o seu projeto é insuficiente devido à falta de uma institucionalização e juridificação do cosmopolitismo. Nesse sentido, indo além de Kant, Habermas propõe atualizar o cosmopolitismo a partir da institucionalização de uma "democracia supranacional" na qual os cidadãos tenham status normativo igual aos Estados nacionais. O fundamento normativo dessa abordagem cosmopolita 
de uma democracia supranacional reside nos direitos humanos que têm por base a moralidade da dignidade humana considerada por Habermas como o "sismógrafo" e o critério universal para uma ordem jurídica democrática e justa. A tese central de Habermas - que consiste no horizonte normativo deste artigo - é que a dignidade humana é a fonte dos direitos humanos (die Menschenwürde ist die Quelle der Menschenrechte). A dignidade humana enquanto moralidade do respeito igual entre as pessoas alimenta normativamente o direito positivo e a legislação democrática, de modo que ela é a "dobradiça conceitual" do direito e da política.

Palavras-chave: Cosmopolitismo, Democracia supranacional, Dignidade humana, Direitos Humanos.

Abstract: The paper discusses the Habermasian articulation between supranational democracy and human rights in the light of Kant's cosmopolitanism. For Habermas, the Kantian proposal of a cosmopolitan law was emblematic, but it is insufficient due to the lack of institutionalization and legalization of cosmopolitanism. In this way, going beyond Kant, Habermas proposes to renew cosmopolitanism from the institutionalization of a "supranational democracy" where citizens have equal status with national states. The normative foundation of this cosmopolitan approach to supranational democracy lies in human rights that are based on the morality of human dignity considered by Habermas to be the "seismograph" and the universal criterion for a democratic and fair juridical order. Habermas' central thesis - which is the normative horizon of this article - is that human dignity is the source of human rights (die Menschenwürde ist die Quelle der Menschenrechte). Human dignity as a morality of equal respect between people normatively feeds positive law and democratic legislation, so that it is the "conceptual hinge" of law and politics.

Keywords: Cosmopolitanism, Supranational Democracy, Human Dignity, Human Rights.

\section{Introdução}

O nosso objetivo principal neste artigo consiste em apresentar uma abordagem acerca da relação entre democracia supranacional e direitos humanos a partir de Habermas e à luz do cosmopolitismo kantiano. 
Articulamos este artigo em três momentos: (i) inicialmente faremos uma contextualização básica do tema da paz perante o realismo e normativismo e sua apropriação filosófica em Kant e Habermas; (ii) em seguida apresentaremos os pontos principais da proposta de Habermas de "democracia supranacional" e de sua ideia de "soberania popular compartilhada" mediante sua reelaboração institucionalista do cosmopolitismo de Kant; (iii) num terceiro momento apresentaremos o esteio normativo da proposta de democracia supranacional que consiste na pressuposição dos direitos humanos e na sua ancoragem na moralidade da dignidade humana.

No que diz respeito à chave de leitura acerca da proposta de Habermas, centraremos nossa abordagem, mormente, em A esteira da tecnocracia, e em Sobre a constituição da Europa, especificamente nos textos sobre a teoria discursiva do direito e do Estado democrático de direito, discurso em prol da solidariedade europeia, e em textos sobre direitos humanos e dignidade humana.

A hipótese central de investigação é que Habermas, apesar de crítico da falta de juridificação do cosmopolitismo kantiano, recolhe do direito cosmopolita de Kant a ideia de uma justiça global e a conecta à sua proposta de democracia transnacional a partir de processos institucionalizados em nível jurídico tendo como vetor normativo precípuo os direitos humanos ancorados na moralidade da dignidade humana.

O escopo empírico de Habermas no seu projeto de transnacionalização democrática é a União Europeia, um projeto ao qual ele pretende oferecer as condições possíveis de sua institucionalização para além de uma mera união comercial, pautando-se em reivindicações democráticas que demandam a superação dos limites do Estado nacional e a implementação de uma soberania cooriginária entre cidadãos e povos dos Estados europeus.

A União Europeia foi pensada inicialmente num contexto pós-guerra em que a Europa termina em ruínas, sobretudo, a partir de um pacto econômico concretizado no Tratado de Roma em 1957. Entretanto, o objetivo de Habermas é que ela seja consubstanciada como uma constituição política para além de suas restrições a determinadas elites econômicas que exer- 
cem poder político - que ele chama de "elite funcional e administrativa" (HABERMAS, 2012, p. 4). Desse modo, ele tenciona que a União Europeia seja plasmada como uma constituição democrática em nível supranacional, algo que a seu ver, opondo-se aos eurocéticos, o Tratado de Lisboa (2007) não estaria tão distante de efetivar.

\section{Realismo, normativismo e a questão da paz}

Apesar de as reflexões sobre a paz e a guerra terem se avolumado no último século, mormente depois das duas grandes guerras mundiais, é possível que a sua problematização filosófica primeva localize-se na Grécia Antiga dentro dos diálogos platônicos, de modo específico, na obra póstuma As Leis ('Ol vouol) em que se trava uma discussão entre o ateniense, o espartano Megilo e o cretense Clínias acerca da função das leis na cidade. $\mathrm{O}$ ateniense defende que o telos das leis é a paz e a ordem, e é confrontado pelo espartano sob a contestação que a paz não passa de um nome vazio sem concretização, ou seja, uma quimera.

Essa visão "nominalista" da paz é expressa do seguinte modo: "o que a maioria dos homens denomina paz, disso tem apenas o nome, pois em verdade, embora não declarada, é a guerra o estado de natureza das cidades entre si" (PLATÃO,

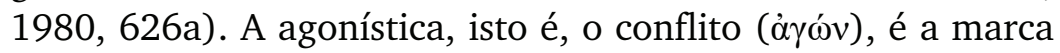
indelével das relações seja do indivíduo consigo mesmo, seja em suas relações intersubjetivas: "na vida pública todos são inimigos de todos, do mesmo modo que, particularmente, cada indivíduo é inimigo de si mesmo" (PLATÃO, 1980, 626d).

Dessa discussão podem-se depreender duas correntes filosóficas para as teorias das relações internacionais, a saber, a realista e a normativista, a primeira considerando a paz uma utopia irrealizável e concebendo as relações como conflito por poder, e a segunda conjecturando a paz como um ideal normativo para as relações, decorrendo daí toda uma gama de esforços com vistas a aproximar-se desse objetivo.

De um modo geral o que será demonstrado ao longo desta pesquisa é a vinculação da posição filosófica de Haber- 
mas à segunda corrente, à normativista, sob o legado kantiano do projeto de paz perpétua. De um modo mais específico, a intenção desta pesquisa consiste em articular a proposta habermasiana de cosmopolitismo à luz dos direitos humanos. Para isso, tomará por base capítulos concernentes ao tema da justiça global, sobretudo, em A Inclusão do Outro, Sobre a Constituição da Europa e Na Esteira da Tecnocracia.

Nesses escritos, Habermas não concorda com a tese do realismo político segundo a qual as relações internacionais devem ser reduzidas a conflitos de interesses e de poder e, igualmente, discorda do modelo neoliberal de Estado que reduz as relações internacionais ao imperialismo e à dominação. Contrapondo-se a essa vertente, ele trilha uma via democrática e normativa e toma como ponto de partida o cosmopolitismo kantiano e sua ideia de justiça global. Todavia, é crítico diante de alguns limites do projeto kantiano cosmopolita, sobretudo, no que concerne ao seu déficit de institucionalidade e juridificação.

Como se sabe, o direito cosmopolita kantiano é uma terceira esfera do direito público; ele, o direito civil e o direito internacional têm a finalidade de assentar as bases jurídicas do ideal normativo da paz perpétua mediante o estabelecimento de uma conditio iuris pública proposta como sendo a superação do estado de natureza que, no prisma de Kant, é uma condição privada sem leis de validade pública com vistas a fazer a mediação normativa das relações entre os indivíduos, em nível de vinculações civis, e entre os Estados, em nível de vinculações interestatais e das relações internacionais. Segundo Kersting (2004, p, 4),

[...] a proteção jurídica interna do Estado pode ser destruída por uma guerra repentina entre os Estados. A liberdade legalmente garantida do indivíduo não depende apenas da estabilidade interna dos Estados, mas também da estabilidade jurídica das relações externas com outros estados. As pacificações interna e externa são interdependentes. Por isso, cada Estado se vê obrigado a completar sua pacificação interna pela condução engajada de uma paz internacional.

Para Guyer (2011, p. 118), a paz entre nações constitui uma meta de justiça global entendida como o supremo bem da política em Kant, como ele mesmo dissera em À paz perpétua. Aproximar-se constantemente do ideal de paz significa, portan- 
to, estabelecer a justiça no mundo. Essa relação entre justiça e paz tem implicações interessantes. Na análise de Forst (2018, p. 130), com isso, Kant fundou uma "ordem normativa", de modo que "a justiça não somente é o fim da paz, mas também o seu meio, como afirmam os três artigos definitivos que versam sobre a ordem republicana no interior dos Estados, a dominação do direito entre eles e o direito universal de hospitalidade como direito da cidadania cosmopolita".

Justiça e paz são "práticas normativas de não dominação" que resistem à dominação política, econômica e militar. "No plano internacional e supranacional, a ordem normativa da paz tem de corresponder a uma ordem de justiça - a justiça constituída juridicamente, baseada em normas legítimas, como enfatiza Habermas junto com Kant" (FORST, 2018, p. 132). Vale ressaltar que o direito internacional público em Kant é normativamente regido a partir do princípio transcendental segundo o qual "todas as ações relativas ao direito de outros homens cuja máxima não se conciliar com a publicidade são injustas" (KANT, 2010, p. 76).

Se no nível ético há o procedimento do imperativo categórico de universalização de máximas, em nível de direito internacional há um princípio transcendental do direito público que averigua a justeza de máximas mediante o critério da publicidade, no sentido que devem ser consideradas justas apenas aquelas máximas dos Estados que venham a público e que de modo transparente, não obscuro, resguardem os direitos humanos, dentre eles, o direito de livre expressão considerado por Kant como um paládio do direito dos povos (KANT, 1980).

O problema que Forst vê nessa proposta kantiana diz respeito ao déficit de justificação, no sentido que Kant ao propor o seu princípio transcendental da publicidade exigiu que a justiça fosse pensada apenas como divulgada e conhecida publicamente, sem demandar a sua justificação intersubjetiva: "contudo, o critério transcendental da publicidade ainda tem de ser interpretado em termos democráticos e práticos, e isto significa que, indo além de Kant, temos de refletir sobre uma justiça democrática para além dos Estados" (FORST, 2018, p. 133). 
Isto é, ainda se trata de uma justiça devedora de um recurso transcendental em que o soberano pensa o justo como se (als ob) os súditos o pensassem, mas sem um processo de justificação normativa entre os sujeitos. Mesmo com essa crítica, Forst não rechaça a relevância de Kant, em especial o legado de seu republicanismo enquanto fomentador de uma cultura de liberdade em contraste com os contextos de dominação não justificada (cf. FORST, 2013, p. 155). Isso pode ser encarado como o núcleo central da tradição cosmopolita.

Kant (2010, p. 41) define o cosmopolitismo como sendo "complemento necessário de código não escrito, tanto do direito do Estado como do direito internacional, para um direito público dos homens em geral e, assim, para a paz perpétua, da qual pode-se aprazer encontrar-se na aproximação contínua sob esta condição." Ele não é uma filantropia, mas um princípio jurídico que deve ter validade no que concerne ao direito do estrangeiro à hospitalidade. "Trata-se aqui, como nos artigos precedentes, não de filantropia, mas do direito, e hospitalidade significa, aqui, o direito de um estrangeiro, por conta da sua chegada à terra de um outro, de não ser tratado hostilmente por este" (KANT, 2010, p. 37).

Hegel, em sua Filosofia do Direito, nas seções sobre direto internacional e soberania exterior, tece considerações sobre o projeto kantiano de paz perpétua e põe sub judice a vulnerabilidade da proposta de Kant de uma federação de paz (foedus pacificum), entendia por ele como sendo permeada pela fragilidade da dependência da adesão subjetiva dos Estados-membros, isto é, tratava-se em sua opinião de uma liga sujeita a "[...] motivos morais subjetivos ou religiosos que dependeriam sempre da vontade soberana particular, e estaria, portanto, sujeita à contingência" (2010, §333). Assim, ela carecia de força objetiva para ser instituída e funcionar adequadamente recaindo numa idealização meramente utópica. Habermas envereda no mesmo caminho da crítica hegeliana e pondera que

Kant não explicou, porém, como garantir a permanência dessa união, da qual depende 'a natureza civil' da harmonização de conflitos internacionais, nem como fazê-lo sem a obrigação jurídica de uma instituição análoga à constituição. Por um lado, ele quer pre- 
servar a soberania dos membros, com a ressalva sobre a dissolubilidade do contrato; é o que sugere a comparação com congressos permanentes e associações voluntárias. Por outro lado, a federação, que fomenta a paz de forma duradoura, deve distinguir-se de alianças passageiras [...] (HABERMAS, 2002, 190).

Desse modo, com Kant além de Kant, Habermas propõe atualizar o cosmopolitismo a partir da institucionalização de uma "democracia supranacional" em que os cidadãos tenham igual peso perante os Estados nacionais e, além disso, grupos e blocos como G7 e União Europeia não sejam conduzidos sob propósitos meramente monetários em detrimento da participação dos cidadãos nas decisões políticas. O substrato normativo deste cosmopolitismo habermasiano remete aos direitos humanos e estes por sua vez têm por base a ideia moral de dignidade humana considerada como um "sismógrafo" e um critério universal para uma ordem jurídica democrática e justa.

Para Habermas, o problema ocorre quando os direitos humanos são instrumentalizados e tomados como subterfúgios por Estados que objetivam meramente estender o seu poder e dominação sobre povos considerados mais vulneráveis e desprotegidos por organismos internacionais, inclusive diante da subscrição da ONU que com certa frequência tem cedido às investidas de superpotências. A eficácia dos direitos humanos requer, destarte, a consideração cosmopolita e universal da dignidade humana de todos os indivíduos entendidos como cidadãos do mundo. Nisso ainda reside o espírito moral kantiano da concepção do ser humano como fim em si mesmo traduzido em nível de normatividade tanto nas relações éticas intersubjetivas quanto em nível institucional de relações políticas globais entre cidadãos e Estados dentro das agendas cosmopolitas.

\section{Cosmopolitismo e democracia supranacional}

Em A esteira da tecnocracia, especificamente, no texto Palavras-chave para uma teoria discursiva do direito e do Estado democrático de direito - texto fruto de seminários dedicados à obra Faktizität und Geltung, proferidos em fevereiro de 2013 no Max Planck Institute para Direito Público Estrangeiro e Direito 
das Gentes - Habermas sob a inspiração de À Paz Perpétua de Kant, tenciona articular a sua ética do discurso com o direito das gentes (Völkerrecht) mediante o propósito da constitucionalização e da juridificação do Ius Gentium pensadas a partir da ideia de uma democracia transnacional e de um cosmopolitismo. Esse projeto se completa com a proposta de uma utopia realista dos direitos humanos escrita em Sobre a constituição da Europa (2012).

No que diz respeito ao cosmopolitismo, Habermas está com e para além de Kant. Kant (2010, p. 41) pensava o direito cosmopolita como um "complemento necessário de código não escrito, tanto do direito de Estado como do direito internacional, para um direito público dos homens em geral", mediante o qual aproximar-se-ia do ideal normativo da paz perpétua em termos de justiça global. A sua tese é que "o direito cosmopolita deve ser limitado às condições da hospitalidade universal" (2010, p. 37); ele versa, destarte, sobre o direito de o estrangeiro não ser hostilizado, desde que este não seja hostil para com o povo visitado. Há, assim, uma reciprocidade. Trata-se de um direito de visita (Besuchsrecht) que não deve ser confundido com um direito de conquista, ou mesmo de exploração dos nativos. Kant era um crítico veemente das potências colonialistas de seu tempo que tomavam o direito de visita como direito de conquista e acabavam por violentar e oprimir os habitantes autóctones.

Compare-se agora a conduta inospitaleira dos Estados civilizados da nossa parte do mundo, principalmente os comerciantes, as injustiças que demonstram na visita a terras e povos estrangeiros (o que para eles vale a mesma coisa que conquistá-los) vai além do horror. A América, os países negros, as Molucas, o Cabo etc., eram, para eles, na época de seu descobrimento, terras que não pertenciam a ninguém, pois contavam os habitantes por nada (KANT, 2010, p. 39).

Habermas entende que essa denúncia de Kant acerca da conduta anticosmopolita dos Estados europeus de seu tempo é bastante significativa porque assinala a precedência de uma opinião pública mundial por parte do cosmopolitismo kantiano. Kant propôs e intuiu bem o direito cosmopolita, porém não foi além em direção a um aspecto central, a saber, a sua juridificação. Sem isso o cosmopolitismo torna-se visivelmente fraco, 
contingente e nada de coercitivo, o que deixa a justiça global numa situação de vulnerabilidade. Por isso que em $A$ inclusão do outro, ao escrever sobre os duzentos anos de À Paz Perpétua, defende a tese que "o direito cosmopolita tem de ser institucionalizado de tal modo que vincule os governos em particular. A comunidade de povos tem ao menos de poder garantir um comportamento juridicamente adequado por parte de seus membros, sob pena de sanções" (HABERMAS, 2002a, p. 201).

Seguindo a pista do cosmopolitismo, Habermas entende que a efetivação da justiça não deve ficar restrita apenas ao nível doméstico dos Estados nacionais: é preciso pensar para além do Estado nacional e, junto com isso, conjecturar a democracia em termos transnacionais. Sobretudo depois da Segunda Guerra Mundial, houve um esforço em avalizar um direito das gentes cooperativo, entretanto, tal cooperação ficou dependente de acordos bilaterais ou mesmo multilaterais sem, todavia, obter um alcance global.

A própria Organização das Nações Unidas se interpôs como mediadora, contudo, arbitrando de um modo fraco, através de resoluções que não obrigam concretamente as nações e, especialmente, as potências mais poderosas a agir de modo justo, daí as guerras incessantes, os problemas climáticos e outros tantos sem solução. Há uma espécie de vácuo normativo (status justitia vacuus) nas relações internacionais em um sentido global (um ordenamento mundial), o que, em termos kantianos, poder-se-ia dizer que os Estados ainda estariam numa situação Unrecht, isto é, num estado de natureza destituído de juridicidade, portanto, sem coerção e validade normativa universal.

Habermas entende que os grupos como G7 - (antigo G8, já que desde março de 2014 a Rússia encontra-se afastada devido a anexação da Crimeia ao seu território) e G20, já constituem bases seminais para uma ulterior constitucionalização do direito das gentes, sobretudo, se são pensados para além do modelo clássico de soberania nacional e dos interesses particulares de um ou outro Estado-membro. A própria União Europeia parece implementar de modo exitoso, mesmo que minimamente, um direito supranacional sob uma base normativa comum de en- 
tendimento entre os Estados participantes e sem o rechaço dos tribunais constitucionais nacionais. O problema da União Europeia no seu prisma é quando ela é conduzida como uma simples união monetária que impõe sanções àqueles que chegam à bancarrota, como se observou recentemente no caso da Grécia.

A grande questão para Habermas é que tais grupos são operacionalizados de um modo fechado, sem a participação democrática dos cidadãos, e conduzidos frequentemente sob uma ótica meramente economicista e imperialista de manutenção global de poder. No seu entender,

em sua forma atual, a União Europeia é tributária do esforço de elites políticas que puderam contar por anos a fio com o assentimento passivo de suas populações, mais ou menos não implicadas, da mesma maneira que os afetados por ela podiam aguardar, no final das contas, também suas vantagens econômicas. A União se legitimou aos olhos dos cidadãos, sobretudo, por seus resultados, e não tanto pela satisfação de uma vontade civil política (HABERMAS, 2014, p. 117).

Há desta forma no entender de Habermas um déficit democrático visível no que concerne à participação da população obstada pela resistência da política neoliberal, o que reverbera num modelo meramente tecnocrático de unidade supranacional. Nesse sentido, ele defende que a transnacionalização da democracia é inadiável. Isso requer que as relações entre Estados e cidadãos pensadas dentro de uma ancoragem democrática e cosmopolita sejam implementadas a partir do que ele denomina "soberania popular compartilhada".

Uma democracia transnacional só é possível mediante o compartilhamento de soberania entre cidadãos e Estados, de modo que participem simetricamente do ato de feitura normativa da constituição fundante, seja em nível de União Europeia ou em nível de sociedade mundial em termos de Nações Unidas. De um ponto de vista do "compartilhamento", da "cooperação cosmopolita", e da "cooriginariedade normativa", a soberania não é uma dominação legal de um ente perante um outro, mas ela significa a reciprocidade no fazer e no seguir as normas.

Nesse modelo de soberania popular compartilhada, as instituições são embasadas numa "coletividade supranacio- 
nal desestatizada", haja vista Estados e cidadãos terem pesos equivalentes dentro deste modelo de participação paritária. "A ideia de que na constituição de uma democracia supranacional podem participar em pé de igualdade cidadãos e Estados (já constituídos por cidadãos) oferece o impulso para refletir sobre uma geometria variável desses componentes" (HABERMAS, 2004, p. 112). A categoria central que se interpõe aqui não é mais a "soberania" intocável, mas a cooperação (Kooperation / Zusammenarbeit). Habermas entende que essa nova configuração provocaria uma reviravolta positiva na própria condução da União Europeia:

As implicações dessa ideia podem ser evidenciadas pelo exemplo da reestruturação hipotética da união monetária europeia em uma união política. Imaginemos uma convenção constituinte que representasse a totalidade dos cidadãos dos Estados europeus participantes, mais exatamente, cada um em sua dupla propriedade como cidadão diretamente participante de uma União Política futura, de um lado, e como membro indiretamente participante de um dos povos europeus, por outro lado [...]" (HABERMAS, 2014, p. 113).

Há, assim, um deslocamento da soberania da centralidade do Estado-nação para o seu compartilhamento entre cidadãos e Estados enquanto entes normativos. Cai por terra o modelo tradicional e desgastado de normatividade estatal alinhada à passividade cidadã. Como já estava posto nos ensaios políticos sobre "A constelação pós-nacional" (2001, p. 64), "a autodeterminação democrática só pode acontecer se a população de um estado for transformada em uma nação de cidadãos que tomam seu destino político em suas próprias mãos". A questão obviamente que se poderia fazer a Habermas é como implementar tal modelo e se os países ditos democráticos, estariam prontos para tal configuração transnacional, haja vista as instabilidades e precariedades ainda em nível doméstico (nacional).

Mas interessa aqui o status da proposta: a transnacionalização democrática implica suplantar o modelo decisionista de soberania estatal; é preciso pensar uma nova ordem global para além do Estado nacional e de um modo amplo para além da própria Realpolitik. A política não pode ser reduzida ao binômio amigo-inimigo como pensou Schmitt (1992), nem res- 
trita ao mero conflito por poder como conjecturou Morgenthau (1948, p. 13) ao afirmar que "relações internacionais, como toda a política, é um conflito por poder. Quaisquer que sejam os objetivos finais da política internacional, o poder é sempre o objetivo imediato". Assim, Habermas (2014, p. 109) entende que "os Estados não podem mais se entender exclusivamente como sujeitos soberanos e contratantes".

Um Estado democrático possibilita aos cidadãos no seu próprio formato constitucional a participação efetiva nas decisões concernentes à vida pública de modo que exerçam com eficácia a sua autonomia política, entendida como a pedra normativa das democracias. O inverso disso é o desgaste dos procedimentos democráticos, a precarização da constituição e o falecimento da participação. Como afirma o próprio Habermas (2001, p. 65), "o estado constitucional democrático, por sua própria definição, é uma ordem política criada pelo próprio povo e legitimada por sua formação da opinião e da vontade, o que permite que os destinatários da lei se considerem ao mesmo tempo os autores da lei”.

Desde o prefácio do ensaio Sobre a constituição da Europa (Zur Verfassung Europas), Habermas já deixa patente sua intenção fundamental de elaborar os elementos para uma transnacionalização democrática: "a comunidade internacional dos Estados tem de progredir para uma comunidade cosmopolita de Estados e dos cidadãos do mundo" (HABERMAS, 2012, p. 5).

Mesmo com idas e vindas do projeto europeu de implementação de uma liga de países condensada sob uma constituição política comum, Habermas, contra os eurocéticos, isto é, contra aqueles que desacreditam da possiblidade de um pacto político transnacional em solo europeu, ainda vê, como dito, na União Europeia a possibilidade de efetivar o projeto de constitucionalização do direito das gentes (ius gentium) em direção a um cosmopolitismo juridificado, seguindo em alguns aspectos e superando e outros os passos do projeto de Kant:

adotando o ponto de vista de uma constitucionalização do direito das gentes, o qual, para além do status quo, aponta com Kant para além de um estado jurídico cosmopolita (kosmopolitischer Rechtszus- 
tand), gostaria de apresentar em seguida uma interpretação nova mais convincente: a União Europeia pode ser concebida como um passo decisivo no caminho para uma sociedade mundial constituída politicamente (HABERMAS, 2012, p. 39-40).

O risco de centrar forças num projeto de gradação cosmopolita restrito a uma determinada região, local e cultura é o de recair em etnocentrismo. É justamente essa a crítica decolonial de Allen a Habermas. No seu entender, o projeto de União Europeia revela a ideia de superioridade civilizatória e a obliteração de outras culturas, o que tornaria inviável pensar em Habermas um cosmopolitismo mais ampliado além do solo europeu.

Em outras palavras, o problema da perspectiva de Habermas não reside no nível de justificação normativa do projeto moral e político do cosmopolitismo kantiano, mas no nível de sua seletividade e aplicação inapropriada (ALLEN, 2016, p. 68).

Retomando a reflexão sobre a dimensão mais normativa do projeto, a transnacionalização democrática requer, em termos de Europa, que o projeto de União Europeia seja repensado para além do reducionismo de perspectiva econômica e que não seja tramado in conclave, isto é, às chaves, a portas fechadas entre burocratas.

A União Europeia se estabilizará no longo prazo apenas se, sob a coerção dos imperativos econômicos, realizar os devidos passos para uma coordenação de políticas relevantes, não no estilo burocrático-governamental até agora costumeiro, mas em direção a uma juridificação suficientemente democrática (HABERMAS, 2012, p. 58).

É necessário integrar os cidadãos europeus nas decisões abrindo, desse modo, um canal interação e comunicação constante com a esfera pública. Essa reivindicação democrática de Habermas não é uma novidade; ela está presente ao longo do conjunto de sua obra como, por exemplo, em Facticidade e Validade onde ele questiona o déficit democrático de validação e legitimidade das normas jurídicas: "a análise das condições da gênese e da legitimação do direito concentrou-se na política legislativa, deixando em segundo plano os processos políticos" (HABERMAS, 1997, p. 9). 
É preciso estabelecer um modelo deliberativo de autodeterminação democrática em que cada cidadão europeu se autocompreenda não apenas como o destinatário, mas também o coautor de uma constituição política da Europa:

autodeterminação democrática significa que os destinatários de leis coercitivas são ao mesmo tempo seus autores. Em uma democracia, os cidadãos são submetidos unicamente às leis que eles mesmos se deram por meio de um procedimento democrático (HABERMAS, 2012, p. 51).

Em termos de democracia transnacional esse procedimento demanda uma relação de complementaridade entre soberania popular e soberania dos Estados em que a sua legitimidade seja efetuada a partir da inclusão de todos os cidadãos nos processos políticos de decisão, no acoplamento da decisão da maioria, e na formação deliberativa da opinião (HABERMAS, 2012, p. 52).

Além desses pressupostos normativos da democracia supranacional que seriam implementados na União Europeia, Habermas não prescinde das condições materiais de existência dos cidadãos e dos Estados membros, havendo assim a necessidade de uma solidariedade supranacional que poderia ser solapada caso subsistissem condições de injustiças sociais: "Uma solidariedade civil em todo o espaço europeu não poderia se desenvolver caso as desigualdades sociais se tornassem estruturalmente constantes entre os Estados-membros" (HABERMAS, 2012, p. 89).

Para corroborar essa preocupação de Habermas para com os mais pobres - o que reforça a sua atenção em relação à dimensão social do cosmopolitismo - nos remeteremos à sua resposta à interpelação de Thomas Assheuer numa entrevista em novembro de 2008 sobre o que mais o inquietava quanto à iminência de uma crise econômica mundial: "O que mais me inquieta é a injustiça social gritante que consiste no fato de os custos socializados do malogro do sistema atingirem da maneira mais dura os grupos sociais vulneráveis" (HABERMAS, 2012, p. 109).

Ou seja, um cidadão do mundo não deve apenas ter a garantia normativa e formal de procedimentos de participação, mas deve igualmente ter a garantia material de uma existência 
digna que torne possível e efetiva o seu agir democrático. Do contrário, esse cosmopolitismo seria mantenedor de injustiças, algo que se distanciaria das pretensões de justiça global pensadas tanto por Habermas quanto por Kant.

\section{A dignidade humana é a fonte dos direitos humanos: die Menschenwürde ist die Quelle der Menschenrechte}

Postos os elementos-chave da proposta de um cosmopolitismo pensado a partir da necessidade de uma transnacionalização democrática para além do modelo político de soberania de Estado-nação, esta pesquisa agora tematizará um aspecto central que será colocado como esteio comum para Estados e cidadãos: os direitos humanos pressupostos como uma pedra normativa em termos de justiça global.

Num dos estudos do ensaio "Sobre a constituição da Europa", Habermas versa sobre "Das Konzept der Menschenwürde und die realistische Utopie der Menschenrechte" (O conceito de dignidade humana e a utopia realista dos direitos humanos), publicado originalmente na Deutschen Zeitschrift für Philosophie (v.58, 2010), tencionando fazer uma articulação entre direitos humanos e dignidade humana mediante a tese segundo a qual a dignidade humana é a fonte dos direitos humanos:

A dignidade humana, que é uma e a mesma em todo lugar e para cada um, fundamenta a indivisibilidade dos direitos fundamentais. [...]. A dignidade humana é um sismógrafo que mostra o que é constitutivo para uma ordem jurídica democrática [...]. A dignidade humana forma algo como o portal por meio do qual o conteúdo igualitário-universalista da moral é importado ao direito. A ideia de dignidade humana é a dobradiça conceitual que conecta a moral do respeito igual por cada um com o direito positivo e com a legislação democrática [...] (HABERMAS, 2012, p. 16-17).

Além da imbricação entre direitos humanos e dignidade humana, Habermas põe a dignidade humana como o eixo central e a base normativa universal do direito e do Estado democrático. Noutra passagem, opõe-se àqueles que veem um prejuízo em tal vinculação, especificamente, na pressuposição de uma moralização dos direitos humanos a partir da intromissão da dignidade humana enquanto teor moral: 


\begin{abstract}
Em contraposição à suposição de que foi atribuída retrospectivamente uma carga moral ao conceito de direitos humanos por meio do conceito de dignidade humana, pretendo defender a tese de que, desde o início, mesmo que ainda primeiro de modo implícito, havia um vínculo conceitual entre ambos os conceitos. Direitos humanos sempre surgiram primeiro a partir da oposição à arbitrariedade, opressão e humilhação (HABERMAS, 2012, p. 11).
\end{abstract}

Um primeiro aspecto trabalhado por Habermas (2012, p. 9) neste tópico é a sua conjectura de que a dignidade humana, apesar de ser um conceito filosófico mesmo que de um modo frágil e en passant comentado no contexto antigo e medieval e apropriado de um modo mais contundente sobretudo na filosofia moral de Kant, fez-se presente de modo especial a partir do século XX quando, tendo em vista a superação normativa dos horrores do holocausto da Segunda Guerra, foram propostas juridificações e incorporação legal da inviolabilidade de direitos fundamentais enquanto medidas protetivas universais dos direitos humanos, medidas estas expressas na Declaração Universal dos Direitos Humanos (1948).

Há, desse modo, enquanto incorporação jurídica nas constituições políticas internas e nas relações internacionais (Ius Gentium), um surgimento tardio do conceito de dignidade humana como conceito jurídico fundamentador dos direitos humanos. A exceção, segundo Habermas (2012, p. 10), se deu, no que se refere à Alemanha, no século XVIII, em março de 1849, no $\S 139$ da Constituição de Frankfurt em torno do debate sobre a abolição da pena de morte e da punição corporal.

Na Alemanha atual, é uma praxe referir-se à dignidade humana para analisar os dilemas vivenciados nos tribunais e na própria esfera pública. O caso citado pelo autor diz respeito à Lei de Segurança Aérea tornada inconstitucional pelo Tribunal Constitucional Federal em 2006. O tema em discussão, ainda efeito das consequências do ataque aos Estados Unidos da América em 2001, versava sobre o seguinte: pretendia-se autorizar as forças armadas em situação símile àquela vivenciada pelos EUA, a abater aviões mesmo que existissem civis inocentes usados como reféns, para assim proteger um número maior de civis em solo. 
A autorização tinha um fundo de argumentação utilitarista no sentido de maximizar o prazer e minimizar a dor para o maior número de pessoas afetadas. Entretanto, o Tribunal a considerou inconstitucional sob o argumento da universalidade da dignidade humana que devia valer tanto para os civis que estivessem no ar quanto para aqueles que estivessem no solo. Não havia uma métrica para dizer quem tinha mais dignidade.

De acordo com Habermas (2012, p. 9), "o eco do imperativo categórico de Kant é evidente nessas palavras do Tribunal. O respeito à dignidade humana de cada pessoa proíbe o Estado de dispor de qualquer indivíduo apenas como meio para outro fim, mesmo se for para salvar a vida de muitas outras pessoas". Isso significa que o utilitarismo não serve para equacionar e solucionar esse problema da Lei de Segurança Aérea discutido na Alemanha em 2006, porque vislumbrando salvar o maior número de pessoas, acaba afetando um menor número, o que implica um cômputo ou cálculo indevido para a proteção universal de direitos.

Nesse caso, o deontologismo de Kant e a sua filosofia moral que toma a dignidade humana como fim em si mesmo (zweck an sich selbst) e o humano como fim terminal (Endzweck) da criação, oferece uma legitimidade mais plausível para os direitos humanos, e Habermas subscreve a essa matriz teórica, apesar de seu projeto de redimensionamento intersubjetivo da moralidade kantiana e de razão destranscendentalizada sob um viés de reconstrução pragmática do universal. Um breve parêntese sobre o conceito de "fim terminal": na Crítica da Faculdade do Juízo, Kant diz que "um fim terminal é aquele que não necessita de nenhum outro fim como condição de sua possibilidade" (KANT, 2008, n. 396, p. 275).

A partir da tese que a dignidade é a fonte moral dos direitos humanos, Habermas entende que não tem sentido o rechaço dos direitos humanos feito pelo realismo político (e cita Carl Schmitt como um dos defensores desse rechaço). Os direitos humanos não são simplesmente utópicos, mas implicam uma "utopia realista" (die realistische Utopie): "os direitos humanos formam uma utopia realista na medida em que não 
mais projetam a imagem decalcada da utopia social de uma felicidade coletiva; antes eles ancoram o próprio objetivo ideal de uma sociedade justa nas instituições de um Estado constitucional" (HABERMAS, 2012, p. 31).

A história dos direitos humanos enquanto direitos institucionalizados numa Declaração Universal em 1948 como consequência de um contexto pós-guerra, na percepção de Habermas dá o tom realista à implementação dos direitos humanos em termos de normatividade global.

A perspectiva de uma sociedade mundial constituída politicamente perde algo de sua aparência de utopia quando nos lembramos que, há poucas décadas, a retórica e a política dos direitos humanos desenvolveram efetivamente uma eficácia global (HABERMAS, 2012, p. 5).

Habermas entende que há um vínculo do "conceito sistemático" dos direitos humanos com o "conceito genealógico" da dignidade humana, gênese aqui entendida no sentido que a violação da dignidade humana promove um impulso e uma luta necessária pela institucionalização de direitos a fim de evitar práticas delituosas e desrespeitosas. Apesar de Habermas não citar textualmente, aqui subjaz a própria ideia honnethiana de luta por reconhecimento, em especial, quando Honneth entende que o desrespeito e o sofrimento são o motor da resistência e da luta por reconhecimento (cf. HONNETH, 2009, p. 224), e tal luta ulteriormente é reverberada em termos de juridificação de conquistas oriundas dessas lutas.

Os céticos perante os direitos humanos devem se dar conta que em hard cases, tais direitos e a dignidade humana são sempre invocados na tentativa de dirimir as dificuldades e desafios em jogo, sejam no plano nacional ou internacional. Óbvio que há questões em torno da sua aplicabilidade, e o risco de contextualmente ser aplicado de diversas formas, entretanto, a base moral da dignidade humana não pode permitir, mesmo em meio a contextos diversos, aplicações que levem a degenerações ou a abusos como massacres, violações, etc., pois isso seria uma contraditio in terminis com os próprios pressupostos da dignidade humana. Relativismo não implica permissão para violações. 
No que diz respeito aos problemas que podem sobrevir da aplicabilidade dos direitos humanos, Habermas (2012, p. 32) adverte contra o mau uso imperialista dessa tipologia de direitos tomada como subterfúgio pelas superpotências para legitimar suas práticas totalitárias. Cita as democracias da América do Sul - qualificadas por ele como "democracias de fachada" - que fazem amiúde um uso retórico dos direitos humanos para justificar políticas usuais de poder que na prática violam tais direitos. E em nível mais global tece uma crítica contundente ao Conselho de Segurança da ONU e aos países imperialistas que manipulam as Nações Unidas para fazer seus caprichos em detrimento de civis:

Lembro o caráter seletivo e monocular das decisões do Conselho de Segurança não representativo, que é tudo menos imparcial, ou a tentativa hesitante e incompetente de impor intervenções autorizadas - e seus oportunos fracassos catastróficos (Somália, Ruanda, Dafur). Essas operações policiais ainda continuam sendo conduzidas como guerras [...]. Quando a política dos direitos humanos torna-se um mero simulacro e veículo para impor os interesses das grandes potências; quando a superpotência empurra para o lado da Carta das Nações Unidas e arroga-se o direito de intervir; quando ela conduz uma invasão que viola o direito das gentes humanitário e a justifica em nome de valores universais, então se confirma a suspeita de que o programa dos direitos humanos consiste em seu mau uso imperialista (HABERMAS, 2012, p. 33).

Há ainda uma questão crucial acerca da fundamentação dos direitos humanos: eles são a priori ou históricos? O próprio Habermas (2012, p. 19) responde a tal interpelação afirmando que "os direitos humanos se diferenciam dos direitos morais entre outras coisas por estarem orientados para uma institucionalização - portanto, devem ser criados - e para isso necessitam de uma formação da vontade comum democrática". Isso supõe uma articulação entre a fonte moral e a juridificação demandada mediante as reivindicações concretas por meio de luta por reconhecimento de parcelas aviltadas de dadas sociedades com vistas à sua proteção. Há uma passagem emblemática onde Habermas (2012, p. 14) ratifica esta sua ideia segundo a qual os direitos humanos, pensados a partir da dignidade humana, nascem e atualizam-se a partir da oposição às práticas de violência e exclusão: 
A experiência de violência da dignidade humana tem uma função de descoberta - por exemplo, em vista das condições sociais de vida insustentáveis e da marginalização das classes sociais empobrecidas; em vista do tratamento desigual de mulheres e homens no mercado de trabalho, da discriminação de estrangeiros, de minorias culturais, linguísticas, religiosas e raciais; também em vista do sofrimento de mulheres jovens de famílias de imigrantes que precisam se libertar dos códigos de honra tradicionais; ou diante da expulsão brutal de imigrantes ilegais ou dos que buscam asilo. À luz dos desafios históricos, em cada momento são atualizadas outras dimensões do sentido de dignidade humana.

Os direitos humanos são, assim, depreendidos a partir de lutas sociais por reconhecimento; são a posteriori. A partir, sobretudo, do século XVIII no contexto do Iluminismo e do subsequente secularismo do Estado, tais direitos foram despidos de um roupagem teológico-metafísica e assumidos como constructos sociais sob uma pretensão de validade universal. Claro que isso não implica automaticamente a perda de referência aos princípios morais da liberdade, igualdade, valor inalienável da vida, dentre outros direitos mais básicos, pensados como intrínsecos ao indivíduo, portanto, independentes de um acordo social que lhes avalizem.

Como apontado acima, o discurso dos direitos humanos como fundamento do cosmopolitismo precisa enfrentar o diagnóstico de Schmitt segundo o qual isso daria espaço a um uso imperialista desses direitos, para esconder interesses escusos. De acordo com Benhabib (2012, p. 698),

Schmitt não está equivocado, então, ao ver no texto de Kant o início de uma visão de uma ordem mundial liberal dentro da qual a gama de regimes que deveriam ser considerados legítimos é reduzida àqueles que deveriam respeitar os direitos das nações definidos mediante os princípios da paz perpétua.

Habermas aceita um nó de verdade no diagnóstico de Schmitt a respeito do cosmopolitismo com base nos direitos humanos que a bem da verdade ele próprio quer defender, e ensaia uma resposta. De acordo com Habermas, o projeto cosmopolita de Kant precisa ser reformulado na direção da defesa de uma democracia cosmopolita com vínculos jurídicos mais fortes e com base nos direitos humanos. Ora, é precisamente 
esse ponto que Schmitt desafia, ou seja, os direitos humanos estariam na contramão de relações jurídicas entre os Estados, pois implicariam uma moralização das relações internacionais que regurgitaria a figura da guerra justa que não contribuiria para a paz, ao contrário, pioraria as guerras.

O ponto de Habermas contra Kant parece ter sido uma insuficiente juridicização das relações internacionais, de tal maneira que ele reformula o cosmopolitismo de Kant em uma direção dupla, normativamente, aprofundando os vínculos com os direitos humanos e, politicamente, no sentido da juridicização que teria sido, ao final, recusada por Kant, pelo menos em um sentido mais musculado.

O ponto de Schmitt é que os dois vieses não só seriam incongruentes, ou seja, direitos humanos e legalidade não combinariam, como piorariam as guerras. Habermas se vê na contingência de responder a essa objeção, até porque, como dito, ele admite um núcleo de verdade no argumento de Schmitt, o que, claro, atinge o seu próprio projeto cosmopolita com base nos direitos humanos.

De fato, uma moralização sem mediações do direito e da política conduziria ao rompimento de zonas protegidas que se quer ver asseguradas juridicamente para os sujeitos portadores de direitos. Não obstante, seria um erro defender que a moralização da política internacional poderia somente ser evitada mantendo-a livre do direito desconectado da moral (cf. HABERMAS, 1998, p. 199), visto tal consideração obliterar fundamentalmente a questão da legitimidade, que Habermas entende em conexão com a democracia e em harmonia com princípios morais.

Mais importante que isso, o ponto central do argumento de Habermas consiste em mostrar que os direitos humanos não seriam morais por natureza, de tal forma que a sua implementação não conduziria a um fundamentalismo moral (cf. HABERMAS, 1998, p. 200). Os direitos humanos não podem ser confundidos com direitos morais. Direitos são zonas de liberdade, não imposição de deveres: "este privilégio conceitual dos direitos sobre deveres decorre da estrutura do direito coercitivo moderno primeiramente elaborado por Hobbes" (HABERMAS, 1998, p. 191). 
Queremos enfatizar que no texto $O$ conceito de dignidade humana e a utopia realista dos direitos humanos, Habermas concedeu uma função importante para o conceito de dignidade humana, no sentido de que ela

[...] forma algo como o portal por meio do qual o conteúdo igualitário-universalista da moral é importado ao direito. A ideia de dignidade humana é a dobradiça conceitual que conecta a moral do respeito igual por cada um com o direito positivo e com a legislação democrática (HABERMAS, 2012, p. 17).

Isso implica duas consequências importantes para as quais Habermas diz não ter atentado em seus trabalhos anteriores sobre os direitos humanos, a saber, à força motivacional da noção de dignidade humana, inclusive como base de revoluções políticas, bem como ao seu papel catalisador (HABERMAS, 2012, p. 12).

Até esse ponto pareceria que o discurso da dignidade humana desempenharia funções importantíssimas, mas não ao ponto de tocarem questões de fundamentação dos direitos humanos. Porém, há um par de afirmações no texto de 2011 que parecem incoerentes, a um, "não acredito que essa reflexão exija uma revisão de minha introdução originária do sistema de direitos [...]", para o que ele remete ao cap. III de Direito e democracia, "deixarei de lado aqui se esse deslocamento do foco para essas questões tem consequências adicionais para minha intepretação deflacionada do princípio do discurso 'D' na fundamentação dos direitos humanos [...]” (HABERMAS, 2012, p. 19), para o que ele remete à discussão havida com Apel.

O ponto está em que Habermas tecera uma crítica severa ao conceito de dignidade humana, o qual ele considerara uma estratégia, não errada, mas insuficiente (HABERMAS, 2002b, p. 523). O ponto insuficiente residiria em um déficit de intersubjetividade, pois a dignidade humana seria vista como uma propriedade intrínseca de cada um, anterior a qualquer socialização, de tal forma que haveria um resquício ontológico não mais aceitável na modernidade. O conceito de autonomia seria melhor vocacionado par a intersubjetividade. 
Ora, o Habermas dos ensaios Sobre a constituição da Europa parece ter corrigido esse ponto do diagnóstico e concedido ao conceito de dignidade humana um viés intersubjetivo, no sentido das lutas políticas contra as humilhações (HABERMAS, 2012, p. 11), o que acabou por atenuar também o caráter ontológico do conceito de dignidade. Com isso a dignidade humana pôde operar de forma mais musculada no seu sistema.

Tendo em vista essa estrutura conceitual, duas questões podem ser postas: a primeira tem relação com a natureza dos direitos humanos. Ao que parece, a dignidade humana é apresentada por Habermas como um conceito moral. Se ela passa a ter função relevante na configuração dos direitos humanos, isso implica que a sua natureza moral conferiria também uma natureza moral aos direitos humanos? Se for assim, como ficaria sua resposta às objeções de Schmitt segundo as quais a fundamentação das relações internacionais conduzidas com base nos direitos humanos pioraria o cenário da guerra, já que a moral daria uma clivagem às contendas em termos de bem e mal, o que tornaria as guerras mais radicais.

Não obstante, este parece não ser o caso, haja vista Habermas não desfazer a possibilidade da formulação jurídica dos direitos humanos. Não só ele reforça o caráter bifronte dos direitos humanos como direitos morais e jurídicos, com remissão à metáfora da face Jano, como concede à dignidade humana justamente a um papel "[...] na mudança de perspectiva que vai dos deveres morais aos direitos jurídicos" (HABERMAS, 2012, p. 20).

A segunda questão diz respeito exatamente a uma mudança de estratégia em relação à fundamentação dos direitos humanos, mormente em relação à neutralidade moral do princípio do discurso, um item central da sua estratégia de fundamentação dos direitos humanos em Direito e democracia. Defende-se que este não é o caso, haja vista o tom do texto ser mais no sentido da gênese dos direitos humanos (cf. HABERMAS, 2012, p. 28).

O que Habermas parece estar a defender é que a dignidade humana teve papel importante no desenvolvimento dos direitos humanos, seja no sentido da sua explicitação, seja no 
sentido da sua implementação, mas isso seria congruente, e não em oposição, com a fundamentação por ele proposta em Direito e democracia com base na forma jurídica e no princípio do discurso. Ademais, o princípio do discurso não pode ser entendido em termos morais por outras razões estruturais da filosofia de Habermas, como aquela de ser o fundamento também das proposições veritativas.

Quiçá Schmitt e Habermas muito embora definam o que seja jurídico em traços kantianos, - já que aquele remete ao elemento da determinibilidade e da consideração das ações, em vez do caráter do agente, e este apela à formulação também kantiana que distingue o direito da moral pela externalidade das relações jurídicas, ou seja, certos aspectos da conduta que seriam franqueados para a moral, como convicções e motivos, seriam infensos a regulamentação jurídica (cf. HABERMAS, 1998, p. 201) -, Habermas parece ter evidenciado um segundo aspecto que ele julga derradeiramente importante, a saber, o direito clama por procedimentos, o que lhe permite a conclusão: "o fundamentalismo dos direitos humanos é evitado não renunciando à política dos direitos humanos, mas apenas através de uma transformação cosmopolita do estado da natureza entre os estados em uma ordem legal" (HABERMAS, 1998, p. 201).

\section{Considerações finais}

Como vimos, o caso exemplar do qual Habermas se ocupou para pensar o cosmopolitismo gradativo foi a União Europeia. Em torno dela ele concentrou seus esforços na tentativa de superar a crítica eurocética da impossibilidade de fundação constitucional da união de Estados e povos soberanos.

De acordo com a perspectiva decolonial de Amy Allen, o cosmopolitismo de Habermas tem suas falhas empíricas porque "sua resposta implica o apelo à necessidade e à inevitabilidade da universalização de normas centrais ao legado do esclarecimento europeu" (ALLEN, 2016, p. 68). Para autora, essa visão provinciana de Habermas oblitera as diferenças culturais, é cego diante da possibilidade de explosão de nacionalismos, além de denotar a superioridade da civilização europeia. 
Em termos mais normativos, afastando-se de Hegel, Habermas não concorda com o centralismo do Estado e pensa as relações entre cidadão e Estado em nível supranacional; nisso se aproxima de Kant, sobretudo, na recepção de seu cosmopolitismo. Entretanto, volta a Hegel no que concerne à crítica da fragilidade da proposta kantiana por ela padecer de um déficit de institucionalidade e coerção jurídica.

Assim, ele reatualiza a ideia cosmopolita de Kant no rol de um plano institucional que culmina na proposta de uma "soberania popular compartilhada" em que cidadãos e Estados compartilham de igual status implementada por meio de uma "coletividade supranacional desestatizada".

Essa reatualização do cosmopolitismo kantiano, por um lado, tenciona suprir o déficit institucional da foedus pacificum, mas, por outro, preserva a inspiração kantiana da relação entre dignidade humana e direitos humanos. Ir além das barreiras do Estado-nação e rumar ao cosmopolitismo não deve ser um passo inseguro; do contrário, esse deslocamento deve ser feito tendo como base a dignidade humana enquanto fonte normativa dos direitos humanos. Como dito anteriormente, Habermas não prescinde do pressuposto que "a ideia de dignidade humana é a dobradiça conceitual que conecta a moral do respeito igual por cada um com o direito positivo e com a legislação democrática" (HABERMAS, 2012, p. 16-17).

O eco do imperativo categórico de Kant segundo o qual os indivíduos devem ser tratados como fins em si mesmos e não simplesmente como meios para outros fins, deve ser contínuo na configuração cosmopolita de uma democracia que se pretende supranacional. Daí a articulação proposta por este artigo entre democracia supranacional, cosmopolitismo e direitos humanos a partir de Habermas e à luz de Kant.

\section{Referências}

ALLEN, Amy. The End of Progress: Decolonizing the Normative Foundations of Critical Theory. New York: Columbia University Press, 2016.

BENHABIB, Seyla. Carl Schmitt's Critique of Kant: Sovereignty and International Law. Political Theory. V. 40, N. 6, (2012), p. 688-713. 
FORST, Rainer. A Kantian Republican Conception of Justice as Nondomination. In.: Andreas Niederberger and Philipp Schink (ed.), Republican Democracy: Liberty, Law, and Politics. Edinburgh: Edinburgh University Press, 2013, p.154-168.

FORST, Rainer. Justificação e Crítica: Perspectivas de uma teoria crítica da política. Trad. Denilson Werle. São Paulo: Editora Unesp, 2018.

GUYER, Paul. Kantian Communities: The Realm of Ends, the Ethical Community, and the Highest Good. In: Thorpe, Lucas; Payne, Charlton. (Editors). Kant and the Concept of Community. [vol. 9 - North American Kant Society]. New York: University of Rochester Press, 2001, p. 88-137.

HABERMAS, Jürgen. Na esteira da tecnocracia: pequenos escritos políticos XII. Trad. Luiz Repa. São Paulo: Editora Unesp, 2014.

HABERMAS, Jürgen. Sobre a constituição Europa: um ensaio. Trad. Denilson Werle, Luiz Repa, Rúrion Melo. Editora Unesp, 2012.

HABERMAS, Jürgen. A inclusão do outro: estudos de teoria política. Trad. George Sperber e Paulo Soethe. São Paulo: Loyola, 2002a.

HABERMAS, Jürgen. Remarks on Erhard Denninger's Triad of Diversity, Security, and Solidarity. Constellations. V. 7, N. 4, (2002b), p. 522-528.

HABERMAS, Jürgen. The Postnational Constellation: Political Essays. Translated, edited and with an introduction by Max Pensky. Cambridge, MA: The MIT Press, 2001.

HABERMAS, Jürgen. The Inclusion of the Other: Studies in Political Theory. Edited by Ciaran Cronin and Pablo de Greiff. Cambridge: The MIT Press, 1998.

HABERMAS, Jürgen. Direito e Democracia: entre facticidade e validade. Vol. 2. Trad. Flávio Siebeneichler. Rio de Janeiro: Tempo Brasileiro, 1997.

HEGEL, G. W. F. Linhas fundamentais da filosofia do direito, ou direito natural e ciência do Estado em compêndio. Trad. Paulo Meneses [et al.]. São Leopoldo, RS: Ed. UNISINOS, 2010.

HONNETH, Axel. Luta por reconhecimento: a gramática moral dos conflitos sociais. $2^{\text {a }}$ ed. Trad. Luiz Repa. São Paulo: Editora 34, 2009.

KANT, Immanuel. À Paz Perpétua. Trad. Marco Zingano. Porto Alegre: L\&PM, 2010.

KANT, Immanuel. Crítica da faculdade do juízo. $2^{\mathrm{a}}$ ed. Trad. Valerio Rohden e Antônio Marques. Rio de Janeiro: Forense, 2008.

KANT, Immanuel. Über den Gemeinspruch: Das mag in der Theorie richtig sein, taugt aber nicht für die Praxis (TP). In: Gesammelte 
Schriften, Vol. VIII. Königlich preussischen Akademie der Wissenschaft. Berlin: De Gruyter, 1980.

KANT, Immanuel. Fundamentação da metafísica dos costumes. Trad. Paulo Quintela. São Paulo: Abril Cultural, 1974.

KERSTING, Wolfgang. Hobbes, Kant, a paz universal e a guerra do Iraque. Kant E-Prints. V. 3, n. 2, 2004, p. 1-13.

MORGENTHAU, Hans J. Politics among Nations: The Struggle for Power and Peace. New York: Alfred A. Knopf, 1948.

PLATÃO. Leis e Epinomis. In: Diálogos. Trad. Carlos Alberto Nunes. Belém: Universidade Federal do Pará, 1980.

SCHMITT, Carl. O conceito do político. Trad. Álvaro L. M. Valls. Petrópolis, RJ: Vozes, 1992. 